as the one that had initiated the disease. It seemed in its course to resemble the rebellious spirit of a man, whose path being made plain, wanders, from a sense of erratic eccentricity, into a violation of all laws and all conventional forms.

Medicine seemed to have lost all influence over the course of the malady. Quinine, considered antagonistic, if not antidotal, had no influence in checking the current of the disease, for in its action it was powerless; the Eucalyptus globulus, so much vaunted of late as possessing properties equal to those of quinine, was, in my hands, worse than useless, for it not only had no influence in checking or antagonising the disease, but it added to the existing distress of the patient by generating nausea and exciting vomiting.

In spite of the radical change in climate, in diet, and in the train of mental thought (to which last I attach much importance and much influence in the cure of disease) which a removal to England had produced, the attacks which were observed months after these men had left the Coast possessed a force as great as the original attack, both in duration and in characteristics. It therefore became a matter of belief to suppose that this successive series of symptoms, though considered to be dependent upon the efforts of nature to eliminate the malarious poison from the system, could only arise from germs originally absorbed remaining behind in the system, renewing, repeating, and multiplying themselves; and when renewed and multiplied, and, having reached a point of maturity, bursting forth into an expression of symptoms similar to those observed before. There seemed in these attacks to be an analogy with those which are observed in the expulsion and the subsequent regeneration of tapeworm; for, after the first seizure, the patient was to all appearance in a state that had the seeming of convalescence, when by a reproduction of the causes, like to the reproduction of the tapeworm, effects similar to the first were evinced.

The cases of remittent fever and dysentery which have been under consideration in the above plain statement bave been characterised by a degree of severity which was attributable to the exceptionable meteorological and cosmic influences, and to unlooked-for circumstances which attended the disembarkation of this detachment of men upon the Gold Coast.

The subjects of these cases had undergone a strict medical examination before leaving the shores of England; they were, therefore, healthy and robust. But the combined adverge circumstances which greeted them after landing on this Coast acted injuriously, and characterised their melancholy history. The men who are now in active duties against the Ashantees have much in their favour which these first men had not; and though casualties under the circumstances will occur, and many evil influences be subjected to, the admirable precautions taken by those in authority, and the instructions placed in the hands of each soldier as to his mode of action on the line of march and in the presence of the enemy, will, it is trusted, serve as an ægis for his protection, and save him from the many dread ills which the poor fellows under our immediate consideration have had the misfortune to endure.

The interest which these notes in their relation offer are found in the ready running of dysentery into remittent and the converse; in the persistence of the symptoms, their renewal, and the long unwearied action of the poison upon the system.

Royal Naval Hospital, Haslar.

\section{A CASE OF RETENTION OF URINE SUC- CESSFULLY TREATED BY PUNCTURE ABOVE THE PUBES.}

By WILLIAM ROSE, F.R.C.S.

THE following case, which lately occurred in my practice, seems worthy of record.

On the afternoon of September 11th, 1873, I was sent for to a farm labourer, aged sixty, who was suffering from retention of urine after recent exposure to wet and cold. About a year previously he had a similar attack, which I easily relieved by passing a lurge prostatic catheter. On the present occasion, however, I could not introduce any instrument, and as the symptoms were not then severe, I ordered him hot fomentations, an opiate, and a full dose of castor oil. (Unfortunately, a warm hath was not practicable in a poor cottage in the country.) I visited him four hours later, and was again foiled in my attempts to pass a catheter beyond the bulb. There was evidently a highly spasmodic condition of the whole canal, the instrument being tightly grasped almost immediately on its entrance, superadded to what seemed some permanent stricture at the bulbous portion of the urethra. The prostate could be felt to be much enlarged, and this condition was present, and I believe gave rise to the previous attack of retention.

On the following morning, finding the bladder greatly distended, and being still unable to pass a catheter, I introduced Mr. Cock's curved trocar, just half an inch above the pubic symphysis, drawing off more than forty ounces of high-coloured ammoniacal urine. The conditon of the prostate precluded any operation per rectum. The patient was greatly relieved. There was no unfavourable symptom after this, or irritation produced by the retention of the canula.

Ten days after the operation, the flow of urine by the urethra being fully re-established, the canula was withdrawn, a pad and bandage were applied, and the patient kept Jying on his back until the opening was healed, which took place in a fortnight.

$\mathrm{He}$ has remained well ever since, and passes his urine in a fair-sized stream. I examined the urethra a month after the operation, and found I could pass with some difficulty \& No. 9 into the bladder.

In this case the retention seems to have been due to an inflammatory stricture occurring in a patient with a preexisting hypertrophied prostate. The fact of the urethra recovering itself without any mechanical dilatation, and afterwards admitting of the passage of a large instrument, shows the absence of a true organic stricture which I presume could never thus disappear.

High Wycombe.

\section{OVARTOTOMY; TWO PREVIOUS TAPPINGS; EXTENSIVE ADHESIONS; OPERATION; DEATH THE FOLLOWING DAY.}

Bx EDWARD MALINS, M.D., HON. MEDICAL OFPICER, BIRIINGHAY LYING-IN CHABITY.

Mrs. B-, aged twenty-nine, married ten years; four children, the youngest being now a little over two years old. The history of the present tumour extended over six years. The patient had resisted repeated exhortations to have it removed, but now requested that the operation might be performed. Emaciation marked, general health much deteriorated. Largest measurement round abdomen, 55 in. from ensiform cartilage to pubis, $30 \mathrm{in}$. Evidence of much solid matter, considerable ascites, and anterior superior adhesions; no indication of pelvic adhesions. She was tapped the first time on June 27 th, 1871 , and exit given to $43 \mathrm{lb}$. of thin serous fluid; and a second time on Oet. 13th, 1871 87 lb. being evacuated. On both occasions she was pregnant.

On Jan. 14th, 1874, ether being administered, an incision was made in the median line about four inches long, the peritoneum opened by a small aperture, and $40 \frac{1}{2} \mathrm{lb}$. of viscid brown fluid allowed to escape. The wound was now opened to its full extent, and the hand introduced; firm adhesions were felt to the upper part of the tumour and parietes; these were partly broken down with the hand. The wound was enlarged to eleven inches, the adhesions exposed, and the firmer dense bands cut through with Richardson's toothed scissors. The tumour was closely connected with the under surface of the stomach, part of the under surface of the liver, and to the transverse colon along its whole length, to some extent also to the ascending and descending colon; some of these were carefully torn through, others divided with the toothed scissors, and where very firm a small patch left. The tumour was polycystic; the contents of the cysts varying, none of the material in the larger ones being fluid enough to flow through the canula. There were no pelvic adhesions; a long thin pedicle springing from the 